\title{
Research on Legal Protection of Patients' Right to Privacy in China
}

\author{
Lu Meng \\ Department of law, Wuhan University of Technology, Luo Shi Road, Wuhan, China \\ 1677893890@qq.com \\ *Corresponding author:
}

Keywords: patients; medical institutions; privacy; legal protection

\begin{abstract}
Because of the development of society, public awareness of rights is constantly being activated, and the citizen no longer merely plays the role of obedience, and the action of protecting rights is becoming more and more conscious. Most notably in terms of health care, the media has reported a large number of cases that patients bring a suit with privacy violations as a matter of recourse to the Court for compensation in recent years. They reflect that the dispute caused by privacy has intensified the conflict between doctors and patients . Therefore, the research on the protection of patients ' right of privacy is of great significance to the protection of personality rights and the solution of existing doctor-patient contradictions. This article is divided into three parts: the cut-in point is the concept of patient privacy, the contents and features. And combined with the present situation of protection and the knotty problems in our country, solutions are put forward. When a complete and systematic protection system is established, the legal protection of patients ' privacy will not be an armchair theory any more.
\end{abstract}

\section{Introduction}

Although a number of laws in China require the protection of patients' privacy, in practice, it is similar to allowing interns to observe an abortion without the patient's permission. The infringement lawsuit against the patient's right of privacy is increasing year by year. The main reason is that the protection of patients' privacy in Chinese legislation is mostly principled at present, and the practicability of patients' privacy protection clauses is not strong, so it is difficult to realize the function of protecting patients' rights. The author hopes to seek a more reasonable and effective civil legal protection system, so as to further strengthen the legal protection of patient privacy in China.

\section{Summary of Patient's Right to Privacy}

\section{1the Concept of Patient's Right to Privacy}

As for the concept of patient's right to privacy, China's relevant legislation is not perfect; scholars also have their own opinions. But there are two main views: the first is represented by scholars Xi Xiaoming and Wang Shengming, who believe that The right to privacy refers to the right of patients to protect their privacy from any form of foreign invasion in the course of diagnosis and treatment. The second view holds that the right to privacy of patients refers specifically to the right to privacy granted to patients by law. In the course of diagnosis and treatment, all kinds of secrets legally held by the patient concerning the individual of the patient shall not be disclosed without authorization, And exclude the doctors from illegally violating their rights.

The author believes that the right to privacy of patients is the product of the special field of privacy and medical care, the most prominent feature of which lies in the specific subject, and only the patient who meets the specific conditions is the subject of the right. Therefore, the right to privacy of patients is summarized as: patients enjoy the right to privacy which has nothing to do with the public interest and the legitimate rights and interests of others in the 
course of medical activities and after the end of the medical activities, which is not illegally infringed by medical institutions and their medical personnel.

\section{2 the Content of Patient's Right to Privacy}

Article 62 of Law of the People's Republic of China on Tort liability that patients have the right of privacy, but the content of the right is not clearly defined, and the academic circles also argue endlessly. The biggest controversy is whether personal information that is not relevant to the treatment of the disease is covered by the patient's right to privacy. The author thinks that personal information belongs to the category of personal privacy, and the personal information which has nothing to do with disease treatment is also protected by law, which is beneficial to the full protection of patients' privacy.

At present, if we want to summarize the content of the patient's right to privacy accurately and comprehensively, the author can only summarize it from the following four aspects after synthesizing the different viewpoints of the scholars. It includes patient's personal information, privacy site, pathological information and private space.

\section{3. the Current Situation of Legal Protection of Patients' Right to Privacy in China}

The Tort liability Law, which has been implemented since July 1, 2010, determines for the first time the legal status of the right to privacy and the right of reputation, and gives special protection to the law. And in the chapter of medical damage liability, the author makes the principle stipulation to the patient's privacy right, and initially forms the rudiments of the patient's privacy protection system.

Section 55 of the Tort liability Act, section 56, covers the right to control the privacy of patients, i.e. the right of patients to disclose their privacy or to allow others to use it. Article 56 is an exemption clause, which stipulates the compulsory right of medical treatment in a critical situation. The right to use privacy refers to the patient's actual needs, Article 61 of the Tort liability Act stipulates that the doctor must make and properly preserve the patient's medical records in accordance with the relevant regulations and that the patient has the right to consult, copy. Medical records, such as medical orders, are personal information, and consulting and copying are one of the positive ways to use them. In fact, this article determines the right to use the privacy of patients.

Through the above analysis, we can see that article 2 of the law establishes the right of privacy as an independent personality right, compared with the protection of the right of privacy compared with other personality interests before, the legislative technology of the Tort liability Law has an essential improvement.

\section{3. the Problems Existing in the Legal Protection of the Right to Privacy of Patients in China}

Firstly, the scope of patients' privacy protection is too narrow. This is reflected in the lack of provisions on patient's right to privacy, deficiencies in the provision of the right to use the Privacy of patients and the provisions on the right to conceal the Privacy of patients need to be improved. In comparative law, personal information includes medical records of course, but the Tort liability Act only stipulates that patients have the right to use privacy and have no right to request privacy supplement, correction or deletion.

Secondly, unresolved coordination issues in cases of conflict with specific rights. For example, The conflict between patient's right to Privacy and Medical staff's right to know ,Conflicts of interest between specific third parties and Conflicts between public interests. How should the right to know of medical personnel be exercised in order to minimize the damage to patients' privacy? How to distinguish which privacy is required to obtain the patient's informed consent, which is the right of medical personnel to know? The existing laws 
of our country still do not have clear judgment standard or principle stipulation in order to coordinate the conflict of the two kinds of rights.

Thirdly, the deficiency of the Civil Relief system of infringing the patient's right to Privacy. "There is damage, there is compensation", in the tort of civil liability, "Tort liability Law" 15 provided for the cessation of infringement, compensation for losses, apology and other eight types of liability. However, China's civil relief system is still imperfect. First of all, according to the law, the premise of moral damage compensation is to cause serious mental damage to others. However, in practice, there is no uniform standard to determine how to be regarded as "serious" mental damage, which is often determined by the discretion of the judge. Due to individual differences, the perception of privacy, acceptance and response to infringements will vary. Therefore, judging whether the mental damage meets the "serious" standard is also a thorny matter for the judge. Because too many cases of "serious mental damage" can lead to a decision that is too radical, and the prudent use of discretion deprives most patients of money the comfort of the medical side, and will contribute to the atmosphere of infringement.

\section{Perfection of Legal Protection System of Patient's Privacy in China}

\subsection{The Legal Principle}

Although the medical person has the right to know the patient's privacy within the scope of diagnosis and treatment. However, the relationship between doctors and patients has its particularity. In order to protect patients' privacy, this kind of "understanding" must be restricted, that is, to follow the legal principle. First of all, the subject of legal, only directly involved in the diagnosis and treatment of medical personnel have the right to know; Secondly, the time is legal, that is, the subject of rights can only be understood during the period of patients receiving medical services, but they still have to abide by the obligation of confidentiality after the end of the medical service activities; Third, the situation is legal, in the case of possible exposure of patients' privacy, diagnosis and treatment activities should be arranged in a more private place; finally, the medical staff understand the patient's privacy The circumference needs to be reasonable and legal, and must not exceed the reasonable scope of the purpose of diagnosis and treatment.

\section{2 make clear the Coordination Rules of Patient's Right of Privacy and Specific Conflict of Interest}

We should coordinate the conflict between patient's right to Privacy and Doctor's right to know by "informed consent". The rule of "informed consent" is not generalized. The medical staff can inform and obtain the consent of the patient in stages, and should understand the patient's privacy within a reasonable scope of diagnosis and treatment. And it is necessary to coordinate other conflicts with the "minimum disclosure" system, the "minimum degree of disclosure" system comes from the fourth legal system in the HIPPA of the United States, which stipulates that the use of patient privacy for other purposes should be minimized and the impact on patients should be minimized as far as possible. This system is to protect the privacy of patients within the reasonable scope of the purpose of diagnosis and treatment by medical institutions and their medical staff.

\subsection{Perfecting the System of Compensation for Infringement of Patients' Right to Privacy}

As for personal injury compensation, section 54 of the Tort liability Act stipulates the fault liability of the doctor in the course of medical service. The improper disclosure or illegal use of patients' privacy will often lead to a decrease in the social evaluation of patients or excessive social concern, resulting in patients suffering tremendous mental stress and causing physical damage, such as insomnia, depression and even mental disorders. The medical expenses, the loss of the wrong work expenses, the nursing expenses and the lawsuit expenses caused by the physical damage are all included in the compensation amount of the personal injury 
compensation, which is stipulated in Article 54 of the Tort liability Law, which stipulates "the patient is injured in the diagnosis and treatment activities".

The damage caused to the patient and his family by infringing on the right to privacy of the patient is often invisible and does not have the direct performance and the concrete criterion of judging the loss as the property loss. As serious mental damage is a prerequisite for compensation for moral damage, how to define "serious mental damage"? The existing reference factors are complex and highly uncertain. In the author's opinion, in legislation and judicature, the fuzzy criterion of "serious" should be desalinated, and the specific circumstances, such as the means of infringement, the consequences of behavior, the subjective fault and so on, should be combined. The mental pain suffered by the patient and his family was determined by the presumption.

\section{Conclusion}

With the development of medical technology and the awakening of people's consciousness of right, the traditional doctor-patient relationship, which is absolutely dominated by doctors, no longer adapts to the development of society. Patients want to recover while privacy is respected. Therefore, under the background of tense doctor-patient relationship and imperfect laws, the discussion of this topic has the dual significance of theory and practice. It is suggested to perfect the Tort liability Law, to expand the scope of protection, to clarify the rules of coordination of interests, and to establish a relatively perfect system for the protection of patients' right to privacy.

\section{References}

[1] Xi Xiaoming,Understanding and Application of the provisions of the Tort liability Law of the people's Republic of China,People's Court Press,vol.1, pp. 232-233, 2010.

[2] Wang Haiyan, The study of the protection of the patient's right to privacy in the hospital management,Health Management in China,vol.7, pp.2-3, 2011.

[3] Wang Zejian,Tort Law,China University of political Science and Law Press,vol.11, pp. 2-4, 2010.

[4] Cui Yan,On the legal protection of patient's right to privacy,Harbin Medicine,vol.6, pp.1-3, 2013. 